\title{
Suitability Evaluation of Ecological Control Measures for Typical Small Watershed Soft Rock Area Based on TVDI and NDVI changes
}

\author{
Jing Liu ${ }^{1, *}$, Li-Ga Bai ${ }^{2}$, Shan Yin², Guo Jianyin \\ ${ }^{1}$ Institute of Water Resources for Pastoral Area of the Ministry of Water Resources of China, Hohhot 010020, \\ ${ }^{2}$ Inner Mongolian Normal University, Hohhot 010020, P.R. Inner Mongolia, China; \\ *Corresponding author Email: mksliujing@163.com
}

\begin{abstract}
The spatiotemporal variation characteristics of soil moisture and vegetation change are important factors to monitor the effect of water and soil loss control in a watershed. Based on the multi-source remote sensing data from 2015 to 2019 , the temporal and spatial variation laws of LUCC, TVDI and NDVI in small watershed are analyzed, and the relationship and change trend of TVDI and NDVI are analyzed by Hurst index. The results showed that: (1) after 5 years of management, the spatial structure of land use, soil moisture TVDI and vegetation coverage NDVI have changed significantly, and the differences of soil moisture and vegetation coverage among different land use types are obvious. The recovery of trees and shrubs accounted for $43.52 \%$ of the total area of the small watershed. (2) The area of extremely humid area in the study area increased significantly, and the extreme drought was alleviated. (3) The mean Hurst index of TVDI and NDVI were 0.47 and 0.62 , respectively. The results showed that soil moisture in small watershed increased as a whole, but the area of soil moisture increased, indicating that the carrying capacity of soil moisture to vegetation decreased in the process of watershed management, which should be paid attention to. The area of NDVI continuous improvement accounted for $43.62 \%$, and the area of degradation to improvement accounted for 9.24\%. The overall vegetation situation in the study area continued to turn better. (4) The statistical order of the suitability area of small watershed management was as follows: high suitable area > more suitable area > unsuitable area. The results show that many years of soil and water conservation measures have greatly improved the regional climate and water conservation capacity, but there are also high vegetation arid areas and large areas of unsuitable areas, which are particularly worthy of attention. It is necessary to reflect the idea of regional soil and water bearing capacity based on water determined vegetation in the future governance planning and allocation, and comprehensively consider the soil, terrain and other factors in the Soft Rock Area we should adjust the management mode in time, scientifically select suitable tree species and measures, and fully consider the necessity, adaptability and sustainability of ecological construction.
\end{abstract}

Keywords: LUCC, TVDI, NDVI, Hurst, Soft Rock Area, Small watershed 


\title{
基于 TVDI 与 NDVI 变化的砒砂岩区典型小流域生态 治理措施适宜性评价
}

\author{
刘静 ${ }^{1}$, 白力嘎 ${ }^{2}$, 银山 ${ }^{2}$, 郭建英 $1^{*}$
}

${ }^{I}$ 水利部牧区水利科学研究所, 呼和浩特, 010020

2 内蒙古师范大学, 呼和浩特, 010020

* 通讯作者. 电子邮箱: mksliujing@163.com

\section{摘要}

土壤水分和植被变化的时空变异特征是监测流域水土流失治理成效的重要因素，本文基于 2015 年-2019 年多 源遥感数据分析了小流域 LUCC、TVDI、NDVI 的时空变化规律，采用 Hurst 指数分析了 TVDI 与 NDVI 相互 关系及变化趋势。结果表明:（1）经过 5 年的治理, 苏布尔嘎小流域的土地利用空间结构、土壤水分-TVDI、 植被盖度-NDVI 都发生了明显变化, 不同土地利用类型土壤水分、植被盖度差异明显。乔灌木林地恢复占小流 域总面积的 $43.52 \%$ 。(2)研究区极度湿润区面积增加明显, 极度干旱减轻。(3) TVDI 及 NDVI 的 Hurst 指数均 值分别为为 $0.47 、 0.62$ 。表明小流域土壤水分整体上升, 但反持续面积的增加, 说明流域治理过程中土壤水分 对植被的承载能力有下降趋势, 应引起注意。NDVI 持续发生改善的面积占 $43.62 \%$, 退化转为改善的面积占 9.24\% , 研究区整体植被情况呈持续转好趋势。(4) 小流域治理适宜性分区面积统计排序为, 适宜区>较适宜 区>不适宜区。结果说明多年的水保措施治理, 对区域气候改善, 水源涵养能力有了很大提升, 但也出现了高 植被干旱区和大面积的不适宜区域, 这是特别值得关注的区域, 需要在今后的治理规划及配置时体现以水定植 被的区域水土承载力思路, 综合考虑砒砂岩区土壤、地形等因素及时调整治理模式, 科学选取适宜树种和措施, 充分考虑生态建设的必要性、适应性、可持续性。

关键词: LUCC, TVDI, NDVI, Hurs, 吪砂岩区，小流域

\section{1 引言}

我国在 2011 年制定的《全国水土保持规划 (2015-2030 年)》总体目标为在我国所有陆地实施 全面预防保护, 从源头上有效控制水土流失, 以维 护和增强水土保持功能为原则, 充分发挥生态自然 修复作用, 多措并举, 形成综合预防保护体系, 扩 大林草植被覆盖。其中重点提出要推广 “以小流域 治理为单元, 实施综合治理” 的防治经验。本文选 取砒砂岩区具有典型性和代表性的小流域作为研 究区域, 运用多源遥感数据对其实施的生态恢复措
施的适宜性进行评价。

土壤水分是陆地与大气直接能量交换过程的 重要因子, 是陆地生态系统循环的重要环节 ${ }^{[1-2]}$, 土 壤水分与植被生长状况密切相关, 对区域生态恢复、 生态系统的稳定性有重大影响。植被盖度的变化情 况对区域生态环境的恢复有指示性作用。因此在整 个流域范围内监测土壤水分与植被覆盖相互之间 的时空变化关系, 对科学评价小流域水土保持综合 治理措施对区域生态系统的修复作用具有重要理 论和现实意义。 


\section{2 研究区概况}

苏布尔嘎小流域位于黄河中游一级支流皇甫川 流域上游，行政区划隶属于内蒙古自治区鄂尔多斯 市准格尔旗暖水乡、沙圪堵镇 ${ }^{[3]}$, 地理坐标为东经 $110^{\circ} 41^{\prime} 35^{\prime \prime} \sim 110^{\circ} 45^{\prime} 00^{\prime \prime}$ ，北纬 $39^{\circ} 45^{\prime}$ $00^{\prime \prime} \sim 39^{\circ} 47^{\prime} 00^{\prime \prime}$ ，按水土流失类型划分属黄土 沟壑丘陵区第一副区; 研究区面积为 $6818.0 \mathrm{~km} 2$, 地 理位置图见图 1。流域属于典型大陆性干旱气候, 年

平均气温 $6.2-7.2{ }^{\circ} \mathrm{C}, \geqslant 10{ }^{\circ} \mathrm{C}$ 积温约 $2900-$ $3500{ }^{\circ} \mathrm{C}$ 。日照强烈, 干旱少雨, 年降雨量 $300 \mathrm{~mm}$ 左右, 降雨多集中在夏季 6-8 月, 占全年降雨总量的 $61 \%$, 且多数为集中性暴雨。冬季大风强烈, 年均风 速 2-3m/s, 大风日数大于 30 天。水蚀风蚀兼有, 土 壤侵蚀严重 ${ }^{[3]}$ 。流域地貌类型属典型的黄土丘陵沟壑

区 $^{[13]}$, 沟内砒砂岩裸露。土壤类型为砂岩及泥岩 土, 土壤养分、水分条件差, 风大沙多, 植物生长 困难稀疏, 物种多样性不丰富, 生态环境敏感。

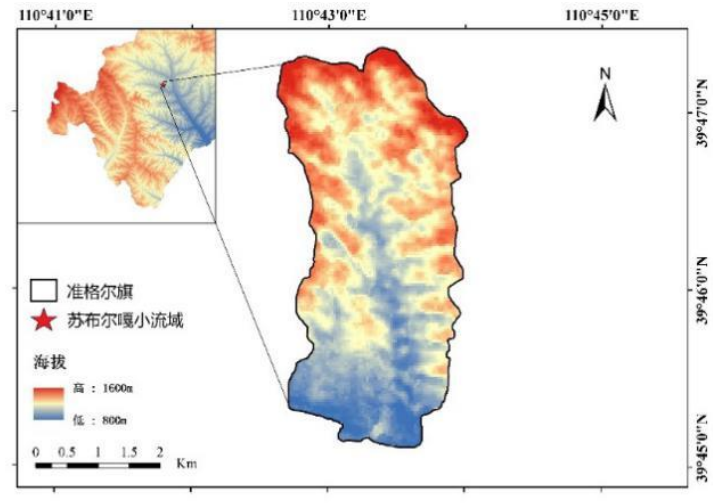

图 1 苏布尔嘎小流域地理位置图

\section{3 数据与方法}

\section{1 多源数据来源及处理}

本文采用 GF-1、DEM、Landsat-8 多源遥感数 据源, 经过投影转换、辐射校正、几何校正等预处 理后备用。其中 GF-1 数据选取 2015 年 7 月和 2019 年 7 月数据, 分辨率为 $2 \mathrm{~m}$ 多光谱和 $8 \mathrm{~m}$ 全色, 用 来人工目视解译研究区土地利用-LUCC。Landsat8 获取时间为 2015-2019 年连续 5 年分辨率 30 米 的多光谱和热红外数据, 用于近地表温度-LST、植 被指数-NDVI、表层土壤水分-TVDI 及 Hurst 指数
计算分析。30 米分辨率的 DEM 数据用来确定研究 区的流域、小流域位置和研究区流域图。

\section{2 土地利用动态变化分析}

采用本文确定的地物分类标准, 按照影像纹理 特征完成目视解译, 本文严格按照技术规范内容图 斑判对率大于 $90 \%$, 小流域实地核查验证图斑大于 $10 \%$ 。在 ARCMAP 中根据解译结果, 分别统计出 2015 年和 2019 年各土地利用类型面积、图斑数、 百分比、图斑的最大值和最小值。通过计算小流域 治理初、末期各土地利用类型面积差值的正负变化 情况, 来量化各土地利用类型动态变化趋势和结构 特征。计算公式为[4-6]:

$$
K=\frac{U_{\mathrm{b}}-U_{\mathrm{a}}}{U_{\mathrm{a}}} \times \frac{1}{T} \times 100 \%
$$

公式 (1) 中, Ua 为研究初期某一土地利用类 型面积, $U b$ 为研究末期某一土地利用类型面积, Uc 为研究时段内某一土地利用类型面积变化幅 度, $U C^{\prime}$ 为年动态度, $T$ 为研究时段。

\section{$3.3 N D V I$ 模型原理及参数计算方法}

植被指数是两个或多个波长范围内的地物放 射率的组合运算, 用以增强植被某一特征或者细节 [7-8]。本文选取宽带绿度指数（Broadband Greenness Index）中的归一化植被指数（NDVI）来 计算, 其计算公式为[9]:

$$
N D V I=\frac{N I R-R E D}{N I R+R E D}
$$

式中: NIR 为近红外波段, Red 为红光波段, 经过波段运算, NDVI 值越高, 代表植被覆盖率越 高。NDVI 的取值范围为-1 1, 一般绿色植被区的 范围为 $0.2 \sim 0.8$ 。

\section{$3.4 T V D I$ 模型原理及参数计算方法}

相关研究表明 $[10-13]$,对于研究区内植被覆盖范 围较大且非均质地表, 可通过遥感影像数据反演地 表温度 LST 和植被指数 NDVI,构建二者的特征空 间 (近似三角形或梯形)，实现区域反演土壤水分 
的估算。其原理为任意一个 NDVI 值均能够对应唯 一一组温度的极值（极大值、极小值），所有最高 温和最低温分别构成特征空间干边和湿边。计算公 式(4) (5)采用杨茹（2020）的相关研究方法[9]。 TVDI 计算公式为:

$$
T V D I=\frac{\left(L S T-T_{\min }\right)}{\left(T_{\max }-T_{\min }\right)}
$$

式中: TVDI 为温度植被指数; LST 为给定像 元的地表温度; Tmax、Tmin 分别为特征空间的干 边和湿边, 对 Tmax、Tmin 进行线性回归, 回归方 程为:

$$
\begin{gathered}
T_{\text {min }}=A_{1}+B_{1} V I \\
T_{\text {max }}=A_{2}+B_{2} V I
\end{gathered}
$$

式中: A1、A2、B1、B2 分别为特征空间干、 湿边方程的截距和斜率, VI 为给定像元的植被指 数。TVDI 的取值范围为 $[0,1]$, 其构成的特征空间干 边对应值为 1 , 湿边对应值为 0 。由于 TVDI 的温 度与植被指数呈负相关关系, 即 TVDI 值越大, 土 壤含水量越低; TVDI 值越小, 土壤含水量越高。

\subsection{Hurst 指数原理及 $R / S$ 分析法计算}

Hurst 指数是用来定义了偏随机游动的统计量, 其意义在于用来度量长时间序列的趋势变化及强 度。其原理为将时间序列 $\mathrm{x} 1, \mathrm{x} 2, \cdots, \mathrm{xn}$ 按子序列长 度 $r=r 1, r 2, \cdots, r m$ 分组。如果子序列长度等间隔分布, 则 $r i=r i-1+d i=2,3 \cdots, m$, 并且 $r m=n / 2$ 的整数部分。 对每一分组, 按 $\mathrm{R} / \mathrm{S}$ 分析法计算可得到统计量 $\mathrm{t}(\overline{\mathrm{RS}}$ 或 SRS)。由此得到数据( $\log \mathrm{ri}, \log \mathrm{ti}) \mathrm{i}=1,2,3 \cdots, \mathrm{m}$ 。 以 $\log \mathrm{ri}$ 为自变量, $\log \mathrm{ti}$ 为因变量, 用此 $\mathrm{m}$ 对数据 做线性回归, 得到的直线斜率及为 Hurst 指数, 计 算在 python 软件中编程实现。Hurst 用 $\mathrm{H}$ 表示, 取 值范围为 $(0,1)$ ，其计算结果意义如下:

（1）当 $0<\mathrm{H}<0.5$ 时，表明时间序列具有长期 相关性, 但将来的总体趋势和过去相反, 即反持续 性。而这种反持续性的强烈程度与 $\mathrm{H}$ 距 0 点的距 离相关, 距离越小, 反持续性越强, 反之, 方持续 性越弱。
（2）当 $\mathrm{H}=0.5$ 时，表明时间序列是随机的不 相关的，现在对未来没有影响。

（3）当 $0.5<\mathrm{H}<1$ 时，表明时间序列具有长期 相关的特征，也就是过程具有持续性。这种持续性 的强烈程度与 $\mathrm{H}$ 距 1 的距离相关, 越接近 1 , 持续 性越强; 反之, 越远离 1 持续性越弱。

（4）当 $H=1$ 时，其时间序列是一条直线，表 明未来完全可以用现在来预测。

\section{4 结果与分析}

\subsection{LUCC 时空变化结果与分析}

研究区 2015 年和 2019 年的土地利用空间分 布情况如图 2、图 3 所示。这种情况表明，小流域 土地利用类型转移状态和情况表明小流域经过 5 年治理, 天然牧草地和灌木林转入量增加明显, 其 中天然牧草地的增加了 $1660.86 \mathrm{~km} 2$ ，主要来源是 裸地和灌木林地, 转化比例分别为 $54.47 \%, 22.23 \%$ 。 灌木林地的新增量 $749.27 \mathrm{~km} 2$, 其主要来源是天然 牧草地和有林地，各占 $49.56 \%$ 和 17.16 。而直得关 注的是裸地转入量中有 $83.26 \%$ 是来源于天然牧草 地。转出减少量最多的土地利用类型是的是裸地、 天然牧草地和灌木林地, 其中裸地有 $83.61 \%$ 转出 为了天然牧草地, 灌木林地则有 $70.14 \%$ 转出为天 然牧草地。公共用地则全部转出为天然牧草地、灌 木林地和有林地。

通过对比研究区的土地利用空间转移结果和 土地利用空间分布图分析, 苏布尔嘎小流情况域由 北向南裸地治理效果最为明显, 转移矩阵表明其转 出为天然牧草地, 表明小流域经过科学规划治理, 区域环境转好, 草地适生性增强, 植被覆盖度增加。 小流域东部大部分侵蚀沟底深达几十米, 治理难度 巨大，均无措施布设，这是大量裸地的主要来源。 


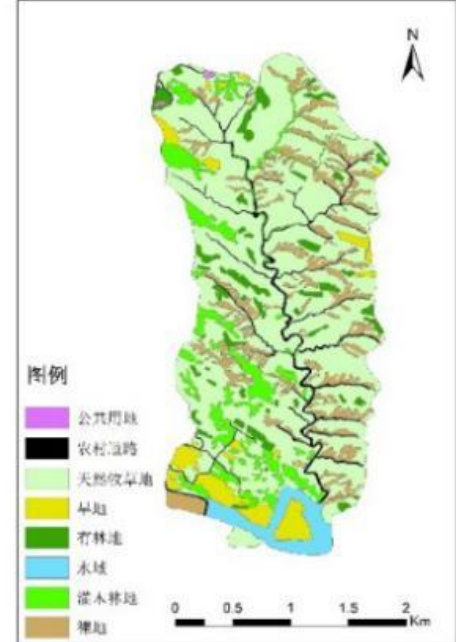

图 2 苏布尔哣小流域 2015 年土地利用空间分布图

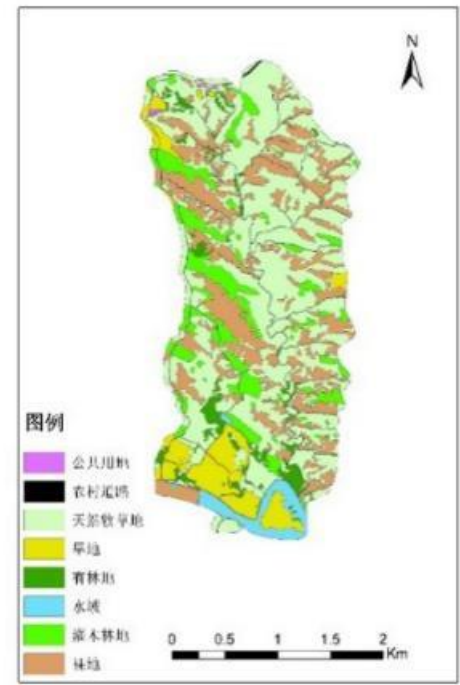

图 3 苏布尔嘎小流域 2019 年土地利用空间分布图

\subsection{NDVI、TVDI 计算结果与相互关系分析}

研究区的 TVDI 与 NDVI 表现出强负相关性, 即随植被指数增加土壤水分减少的植被高需水规 律和地表植被蒸散规律。由于反演时间为植被生长 最旺盛期, 地表温度高且蒸发强烈, 植被需水量高, 研究区出现片状分布的高 NDVI 高 TDVI 区域, 也 就是高植被干旱区域, 面积高达 $14.23 \%$ 。研究区 2015 年土壤含水量总体集中在 $[0.4,0.8]$ 区间内，到 2019 年土壤含水量则总体集中在了 $[0.2,0.7]$, 研究 区的 TVDI 下降，干旱区域减少，极度干旱消失，
土壤水分整体呈上升趋势。研究区极度湿润 （TVDI $<0.15 ）$ 的面积由 $12.85 \%$ 增加到 $27.90 \%$, 干旱和极度干旱（TVDI $>0.60$ ) 总面积由 $43.74 \%$ 减 少为 $42.79 \%$, 研究区干旱减轻。湿润及正常区域 面积明显增加。

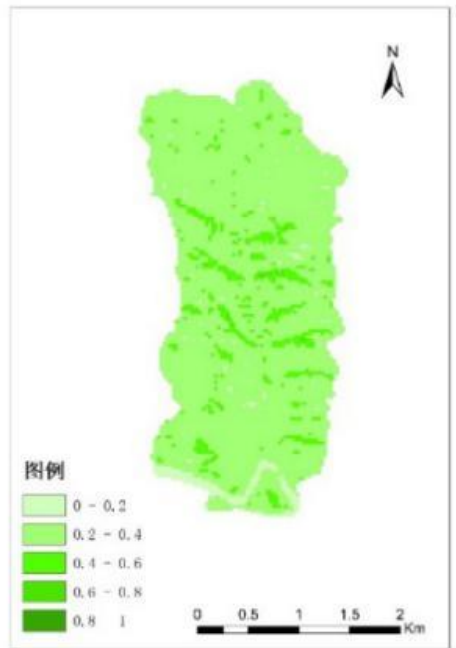

图4＼cjkstart苏布尔嘎小流域2015年NDVI空间分布图

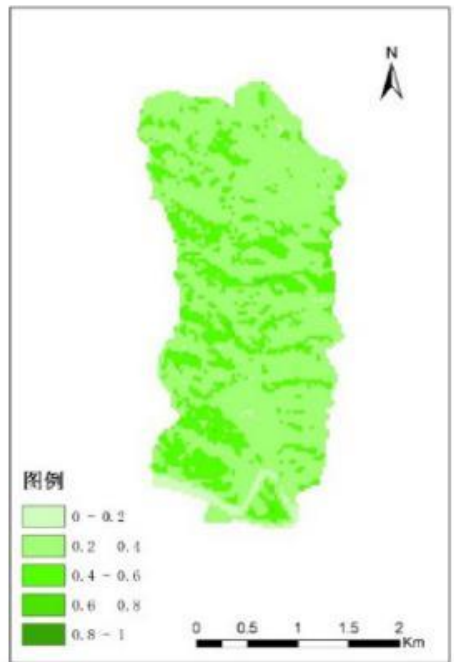

图5＼cjkstart苏布尔嘎小流域2019年NDVI空间分布图 


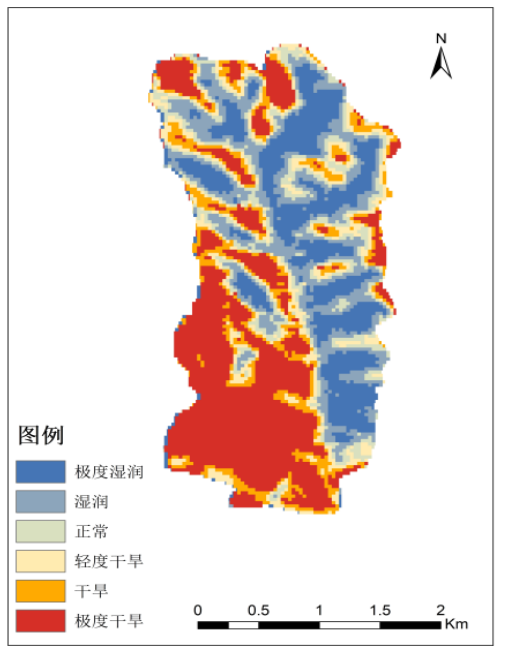

图6 苏布尔嘎小流域2015年TVDI空间分布图

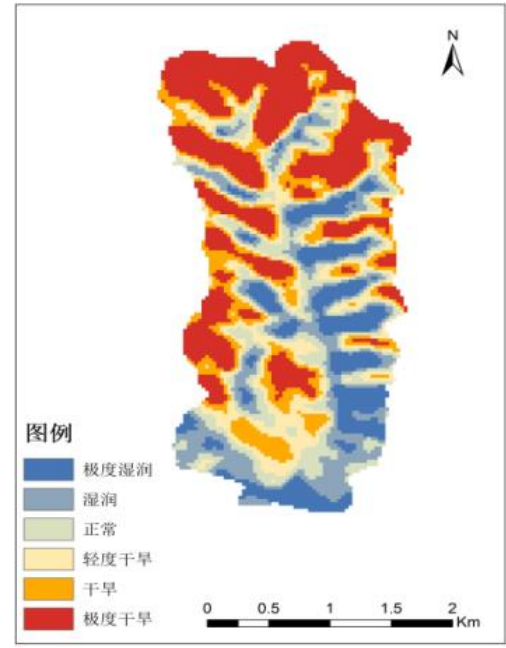

图7 苏布尔嘎小流域2019年TVDI空间分布图

\subsection{Hurst 指数计算结果与变化趋势分析}

本文用Hurst指数描述植被恢复或退化的可能性。将 Hurst计算结果与NDVI、TVDI叠加分析, 划分出等级 来评价生态治理措施的适宜性, 按照TVDI下降NDVI 增加, 生态环境质量转好, 生态恢复力增强, 生态适宜 性增加的分类原则。将研究区分为高适宜区 $(0.5<\mathrm{H}<1)$ 、 中等适宜区 $(H=0.5)$ 、低适宜区 $(0<H<0.5)$ 。NDVI多年 的Hurst指数均值为 0.62 , 根据NDVI的未来变化特征, NDVI持续发生改善的面积占 $43.62 \%$ ，退化转为改善 的面积占 $9.24 \%$, 研究区整体植被情况呈持续转好趋 势。

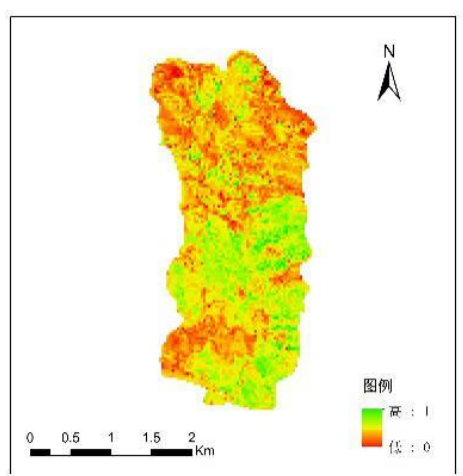

图 8 苏布尔嘎小流域 2015-2019 年 Hurst 变化趋势

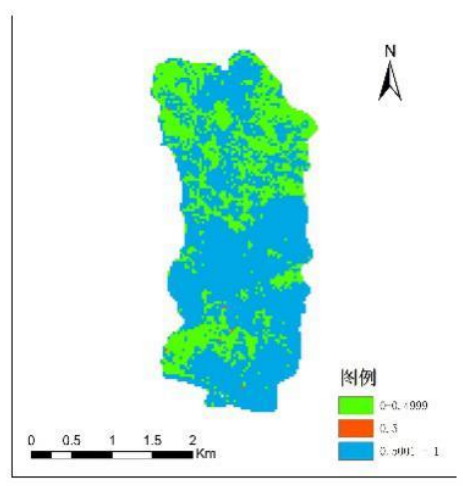

图9 苏布尔嘎小流域2015-2019年生态适宜分区图

\section{5 结论}

本文以砒砂岩区典型小流域综合治理区域的 水土保持植物措施的生态适宜性评价为目的。通过 运用多源遥感数据反演计算了苏布尔嘎小流域 LUCC、TVDI、NDVI 的时空变化数据,并通过 R/S 分析法计算了长时间序列 NDVI 的 Hurst 指数, 协 同分析了 TVDI 与 NDVI 变化及相互之间的影响情 况。最终根据 Hurst 指数的等级划分, 对研究区的 生态适宜性进行了分区描述、评价。得出以下结论：

（1）经过 5 年的治理，苏布尔嘎小流域的 LUCC、TVDI、NDVI 都发生了明显变化，不同土 地利用类型 TVDI、NDVI 指数差异明显。土壤水 分规律总体表现为随植被指数增加土壤水分降低 的趋势（高植被覆盖度高需水量规律）, 其土地利 用类型主要为乔灌木林, 占小流域总面积的 $43.52 \%$ 。

(2)土壤水分 TVDI $<0.15$ 的面积由 $12.85 \%$ 上 升至 $27.90 \%$, 极度湿润区面积增加明显; TVDI > 0.6 的面积由 $43.74 \%$ 下降至 $42.79 \%$, 极度干旱减 轻。主要分布在小流域南部; 流域北部有小面积土 壤水分下降区域, 流域整体 TVDI 显著增加, 在北 
部有经过治理后湿润度明显提高。

(3) 研究区 TVDI 的 Hurst 指数均值为 0.47 , 根据 TVDI 的未来变化特征, 小流域土壤水分整体 上升。但反持续面积的增加, 说明流域治理过程中 土壤水分对植被的承载能力有下降趋势, 应引起注 意。NDVI 的 Hurst 指数均值为 0.62 , 根据 NDVI 的未来变化特征,NDVI 持续发生改善的面积占 $43.62 \%$, 退化转为改善的面积占 $9.24 \%$, 研究区 整体植被情况呈持续转好趋势。

(4) 小流域治理适宜性分区面积统计排序为, 高适宜区 $>$ 中适宜区 $>$ 低适宜区。结果说明多年的 水保措施治理, 对区域气候改善, 水源涵养能力有 了很大提升, 但也出现了高植被干旱区和大面积的 不适宜区域, 这是特别值得关注的区域, 需要在今 后的治理规划及配置时体现以水定植被的区域水 土承载力思路, 综合考虑砒砂岩区土壤、地形等因 素及时调整治理模式, 科学选取适宜树种和措施, 充分考虑生态建设的必要性、适应性、可持续性。

\section{参考文献}

[1] ROUSE $\mathrm{J}$ W,HAAS R H,SCHELL $\mathrm{J}$ A,et al. Monitoring vegetation systems in the great plains with E R T[C]/Proceedings of the Third Earth Resources Technology

Satellite-1 Symposium,Greenbelt,MD,USA, 1973: 3010-3017.

[2] PRICE J C.Thermal inertia mapping: a new view of the earth[J]. Journal of Geophysical Research,1977,82(18): 2582-2590.

[3] 孙特生,李波,张新时.北方农牧交错区农业生态系 统生产力对气候波动的响应-——以准格尔旗 为例.生态学报,2012,32(9):6155-6167.
[4] 孟晋杰,王建华. 高分一号影像数据城市生态用地 监测[J].测绘科学,2016,41(9):33-37.

[5] 郭燕,武喜红,程永政, 等. 用高分一号数据提取玉 米面积及精度分析 [J].遥感信息,2015,30(6):31-36.

[6] 李成蹊,肖鹏峰,冯学智,等.用高分一号卫星数据识 别多时相山区积雪[J].遥感信息,2017,32(2):71-78.

[7] IDSOS B,JACKSON R D,PINTE R J P J,et al. Normalizing the stress-degree-day parameter for environmental variability[J].Agricultural Meteorology,1981,24:45-55.

[8] JACKSON R D,IDSO S B, R EGINATO R J,et al.Canopy temperature as a crop water stress indicator[J].Water Resources Research,1981,17(4): $1133-1138$.

[9] 杨茹,高超,查芉郁等. 不同植被指数在基于 TVDI 方法反演土壤水分中的应用 $[\mathrm{J}]$. 测绘与空间地 理信息,2020,43(02):33-37.

[10] 赵杰鹏,张显峰,廖春华,等.基于 TVDI 的大范围 干旱区土壤水分遥感反演模型研究 [J].遥感技术 与应用,2011,26(6): 742-750.

[11] 徐沛,张超.土壤水分遥感反演研究进展 [J].林业 资源管理,2015(4):151-156.

[12] 王植,陈炟君,董斌.基于 TVDI 的 2013-2017 年沈 阳市旱情等级评估 [J]. 测绘与空间地理信 息,2018,41(11):12-17.

[13] 路中,雷国平,马泉来,等.基于重构的 Landsat-8 时 间序列数据和温度植被指数的区域旱情监测 $[\mathrm{J}]$. 水土保持研究,2018,25(5):371-384. 